\title{
Development of Cost-effective Mosquito Repellent and Distribution Method by Extracting Patchouli Oil
}

\author{
Woo-Taeg KWON*, Lee-Seung KWON**, Ho-Gil YOO***, Woo-Sik LEE****
}

Received: November 11, 2019 Revised: November 25, 2019 Accepted: December 05, 2019

\begin{abstract}
Purpose : We will develop the distribution method of wide oil extract technology to develop repellent using this technology and study mosquito repellent persistence. Research design, data and methodology : A positive control group containing purified water, ethanol and picaridin was prepared, and the experimental control group was prepared in the same proportion as the positive control group, and $0.6 \%$ of broad oil was added. The results were summarized using the calculation method according to the avoidance effect and statistically tested by t-test using the excel statistics program. Results : Experiments on skin surface area and voice control of participants showed that men had $8.9 \%$ wider skin surface area than women, and voice control tests showed that women were bitten by mosquitoes five times more than men. Both the positive and the experimental control groups had a valid duration of up to three hours, but from the time of five hours, the positive control group had $77 \%$ and the experimental control had $90 \%$, indicating a difference of $14.4 \%$ over the positive control group. Conclusions : The mosquito repellents developed in this study on the basis of safety and continuity are cost-effective in terms of mosquito repellent, and in addition fragrance, odor removal, perfume, ink, skin care and massage effect.
\end{abstract}

Keywords: Picaridin, Patchouli oil, Mosquito, Repellency, Avoidance agents

JEL Classification Code: M10, M15, M16

\section{Introduction}

The most dangerous animal to humans is mosquitoes. According to the statistics of the Bill \& Mulley's Gates Foundation, out of about 200 million people infected with malaria, one child under 5 years of age dies from malaria

1 First Author. Professor, Department of Environmental Health \& Safety, Eulji University, Korea. Tel: +82-31-740-7230. Email: awtkw@eulji.ac.kr

2 Second, Author. Professor, Department of Health Care Management, Catholic Kwandong University, Korea. Tel: +82-33649-7274. Email: leokwon1@cku.ac.kr

3 Third Author. Professor, Department of Sports Management, Catholic Kwandong University, Korea. Tel: +82-33-649-7249. Email: yoo2hk@cku.ac.kr

4 Corresponding Author. Professor, Department of Chemical \& Biological Engineering, Gachon University, Korea. Tel: +82-31750-5594. Email: leews@gachon.ac.kr

c Copyright: Korean Distribution Science Association (KODISA)

This is an Open Access article distributed under the terms of the Creative Commons Attribution NonCommercial License (https://creativecommons.org/licenses/by-nc/4.0/) which permits unrestricted noncommercial use, distribution, and reproduction in any medium, provided the original work is properly cited. every minute. Every year, about 10,000 women and 200,000 newborn infants under one year are threatened, increasing fear of mosquitoes. There are more than 3,000 mosquitoes around the world, among them the most damaging to humans: forest mosquitoes (Aedes), cules and malaria mosquitoes(Anopheles). 53 kinds of mosquitoes are known in Korea. With the recent popularity of well-being and well-dying around the world, it is imperative that the development of an active substance with good reluctance be developed in order to develop a new type of eco-friendly and safe mosquito repellent certification that can replace conventional mosquito insecticides, repellents and avoidance agents. Patchouli plants contain a variety of substances, including phenol compounds, terpene compounds and alkaloids. This substance is recognized as a means of IPM (integrated pest management) in that it is selective to pests, relatively harmless to living and environment, has various functions on various pests, and can be treated to crops in the same way as synthetic ones. In addition, plant extracts are characterized by low-impact and 
emerging as a safe and new alternative to the environment as they are easily photosensitive to the natural conditions and quickly lose toxic substances in the plant. The $21 \mathrm{st}$ century is also called the "era of fragrance," and it is a necessary product in the current market situation where the demand for natural essential oil is increasing, and the development of mosquito repellent products using essential oil in the mining direction of natural plants in Korea is converted to organic market. Viruses infected by mosquitoes, mites, encephalitis, and flies cause aftereffects (e.g., Zika virus, dengue fever, etc.) and are not yet available with a valid vaccine, requiring personal immunity from mosquito-borne disease. With the emergence of new infectious diseases such as the Zika virus, domestic production of mosquito repellent and other preventative products reached 87.4 billion won in 2016, up $36 \%$ from 2015 (Ministry of Food and Drug Safety, 2016 statistics). Not only Korea, but also India, Hong Kong, Vietnam, Malaysia, Hungary, and the United States are seeing an increasing number of disease-infected people, and the market demand for environmentally safe and humanresistant products is increasing gradually (Korea's overseas market trend).

Of the mosquito and bug repellents developed so far, DEET (N-diethyl-meta-tolumide) is the most widely used synthetic vaporizer, which stimulates the skin with its own unpleasant odor and irritation, which can cause seizures in infants and children and gradually limit the concentration of use in developed countries (Tox-info; Toxicity information service system). In addition, citronella and cloves are not only less effective than conventional chemicals, but they are also banned by the EU as a mosquito repellent because of the possibility of cancer caused by methyl-eugenol compounds(Korea Consumer Agency).

Indonesia, a major producer of the direction of mining (other name of mining direction: used in patchouli, perfume and cosmetics), accounts for about $50 \%$ of the world's production and Korea is the 17th largest importer of patchouli oil as of 2014 (Central Board of Statistics, prepared by DGNED). Against this background, we aimed to promote and develop safe and healthy human life from the threat of mosquitoes by developing localized production of broad oil and natural mosquito repellent using it on the basis of cost-efficiency.

\section{Literature reviews}

\subsection{Current status of avoiding substances}

Table 1 shows characteristics of repellent ingredient. Drugs used to prevent harmful insects from accessing the human back, and those widely studied and used among dodgers refer to vampire pests such as mosquitoes and mites. Mosquito Peasants are not effective in killing mosquitoes themselves, but they are used to spray or apply substances they dislike on their skin or clothes to prevent them from approaching.

Table 1: Characteristics of Repellent Ingredients

\begin{tabular}{|c|c|}
\hline $\begin{array}{l}\text { Repellent } \\
\text { ingredients }\end{array}$ & Characteristic \\
\hline DEET & $\begin{array}{l}\text { The age limit depending on the concentration } \\
\text { High concentration product over } 10 \% \text { over } 12 \\
\text { years old } \\
\text { Low concentration of less than } 10 \% \text { : Prohibited } \\
\text { under } 6 \text { years old } \\
\text { Prolonged exposure: Delirium, skin rash, hives, } \\
\text { numbness }\end{array}$ \\
\hline Clove oil & \multirow{2}{*}{$\begin{array}{l}\text { Essential oil, some skin allergies } \\
\text { Contains methyl eugenol }\end{array}$} \\
\hline Citronella oil & \\
\hline $\begin{array}{l}\text { IR3535(Ethyl } \\
\text { butyl acetyl amino } \\
\text { propionate) }\end{array}$ & $\begin{array}{l}\text { Similar to beta-alanine structure } \\
\text { Odorless, High stability } \\
\text { Used from kids to adults }\end{array}$ \\
\hline Icaridin & $\begin{array}{l}\text { Colorless, odorless, used from kids to adults } \\
\text { High stability }\end{array}$ \\
\hline
\end{tabular}

\subsection{Current status of non-medical products such as mosquito repellent in Korea}

There may be significant differences in the efficacy and duration of mosquito repellent. In general, the Centers for Disease Control and Prevention (CDC) says that "the higher the concentration of an active ingredient, the longer the effect lasts," but the higher the concentration of the active ingredient does not mean that the product is more likely to avoid mosquitoes. phthalate dimethyl, 2-ethyl-1, 3hexandiol, indalon, dimethyl carbonate (U.K., dimethyl carbonate). According to the Korea Consumer Agency, 30 products with mosquito repellent and mosquito repellent were found to have only one product marked with age limit, and some products sold on the market contain harmful ingredients. Applied alone or mixed to the skin, has an antidamping to prevent access to mites, etc. stained with military clothing, and during the Korean War, benzoic acid benzoyl, N-butyl acetanilide, 2-butyl-2-ethylene, 3-butyl-2ephanyol, and In 2016, seven types of mosquito repellent items are available, most of the 196 licensed products are diethyl toluamide (DEET, 105 products), Icaridin (34 products), junghyang oil (49 products), ethyl butyl acetylamino fionate (4 products), p-Menthane-3, 8-diol oil products (two products), Fennel oil (one product), and Linalool oil(one product)(Ministry of Food and Drug Safety, "Status of mosquito repellent items, as of March 15, 2016)". The trend of non-pharmaceutical products on products of domestic avoidance agents was identified as 105 licensed products in 2016, down -1 from 106 products, +7 from 27 
products to 34 products, and +8 from 57 products to 49 products from 57 products, while Citrouille was released in 2015 but was cancelled from its 2016. Since there are few mosquito repellent products that are mainly natural ingredients, it is understood that most of them have been synthesized into seven types of effective ingredients and released as "smell" products, which are safe and safe for the human body, increasing. The use patterns of domestic dodgers are mainly spray and gel type and are used in conjunction with table 2 .

Table 2: Type and Scent of Repellent Ingredients

\begin{tabular}{|c|c|c|c|}
\hline Type & Spray & Cell type & Spray \\
\hline Scent & Fennel oil & Weak fragrance & Clove oil \\
\hline $\begin{array}{c}\text { Example of } \\
\text { use }\end{array}$ & & & \\
& & & \\
\hline $\begin{array}{c}\text { Application } \\
\text { area }\end{array}$ & $\begin{array}{c}\text { Arms, legs, nape, } \\
\text { clothes, socks, } \\
\text { shoes }\end{array}$ & $\begin{array}{c}\text { Arms, legs, } \\
\text { nape }\end{array}$ & $\begin{array}{c}\text { Arms, legs, } \\
\text { nape, clothes, } \\
\text { socks, shoes }\end{array}$ \\
\hline
\end{tabular}

\subsection{Major components of mosquito repellent}

Repellent ingredients is suggested as table 3. In 2014, 218 mosquito repellents used in Korea are licensed, and most of them use diethyl toluamide (DEET, 106 products), purified oil (57 products), Icaridin (27 products), citronella oil (10 products) as their effective ingredients, and consumers need to check their effects, safety, and advantages and disadvantages. Due to continuous controversy over safety such as side effects of neural system, Diethyltoluamide (DEET), which is commonly used in most countries, is limiting amount, frequency, and age of use. Although national regulations vary on the validity of mosquito skin other than DEET such as Icaridin, citronella oil and cloves oil are allowed in Korea and the U.S., the European Union, Canada and other countries are considering the use of methyl - eugenol, which is contained in the oil.

In the U.S., it allows the sale of junghyang oil. However, the U.S. does not include only components that have been assessed for safety and efficacy, and the U.S. requires companies to submit safety and efficacy data to the Environmental Protection Agency (EPA) for approval in order to include certain ingredients in the list of mosquito control permits. Some natural oils, including cloves, are classified as low-risk pesticides, exempting product registration and allowing sale, but products not listed on the Permit List do not warrant the validity of such products by EPA.

Table 3: Repellent Ingredients in each countries

\begin{tabular}{|c|c|c|c|c|}
\hline Ingredients & Korea & U.S.A & Canada & E.U \\
\hline Icaridin & $\circ$ & $\circ$ & $\circ$ & $\boldsymbol{\Delta}$ \\
\hline Citronella oil & $\boldsymbol{\Delta}$ & $\circ$ & $\boldsymbol{\Delta}$ & $\times$ \\
\hline Clove oil & $\circ$ & $\times$ & $\times$ & $\times$ \\
\hline \multicolumn{2}{|c|}{ ○: Permission $\Delta$ : Review of permission $\times$ : Notpermission } \\
\hline
\end{tabular}

\subsection{Use of the ingredients of the avoided agent and its pros and cons}

\subsubsection{Deet}

It was first used for military purposes as the most commonly used insect repellent, but more recently, its use has been increasing due to an increase in outdoor activities. It used to prevent insect bites by spraying on exposed skin or clothing etc. Some argue that insects have a way of expelling insects because they dislike the smell, while others argue that it is effective to expel insects by blocking their odor receptors from getting in contact with human sweat or breathing. It can cause skin irritation and, in rare cases, can act as a central nervous system such as seizures. When reusing, it is recommended to wash and use the first one and not use it if there is a scar on the skin. There is an age limit according to the concentration level (for highconcentration products over $10 \%$ / for low-concentration products below $10 \%$, for infants under 6 months, for infants under 6 years of age). Prolonged exposure causes side effects such as delirium, skin rash, rash, blisters, blisters, dry mouth, and paralysis.

\subsubsection{Jung hyang oil}

Junghyang belonging to the carendula family is an evergreen small tree flower belonging to the family Eugenia caryophyllata Thunb and myrtaceae. In September, it is ripened with $9 \mathrm{~mm}$ to $12 \mathrm{~mm}$ long flower buds, flower sacks and leaves, which are obtained by distillation of water vapor, which are characterized by a spicy flavor. The plant is native to the Moluccas Islands and is now grown in Madagascar, Pemba, Penang and Malacca. The lactation rate includes 17 to $20 \%$ for oil refining in bud, $6 \%$ for oil refining in flower sacks and 2-3\% for oil refining in leaves. Because of its unique strong aroma, cloves are widely used as a flavoring agent for food and as a directional material in the industry of cosmetics and pharmaceuticals, and have been reported for the antioxidant, salivary, anti-cancer, aromatic, and anti allergenic effects of eugenol, the main aromatic ingredients. The main ingredients are eugenol (70\% 
to $90 \%$ ), acetic acid eugenol, caryophyllene, vanilla, salicylic acid methyl, methyl n-amyl ketone, methyl heptyl ketone, methyl heptyl carbinol, purpureal and methylpyral. Plant oils, some of which cause skin allergies, and may contain methyl eugenol, a carcinogenic substance, in the oil refining compound.

\subsubsection{Citronella oil}

Methyl-eugenol included in citronella oil is classified as a human carcinogenic substance (IARC Group 2B), and contains approximately 1\% methyl Eugenol (if 2 substances are causing concern for humans and lack sufficient information on the mutant category). The $4 \%$ product has a mosquito skin effect of about 1 hour, and ingredients such as geraniol, citrouille, limonene, linalool, and panesol in the oil may cause skin allergies. Some of plant oil contain methyl eugenol, a carcinogenic substance, among the ingredients that cause skin allergies.

\subsubsection{Icaridin}

Picaridin (also known as KBR 3023, Icaridin or Saltidin) is similar to a component called piperin extracted from black pepper trees and is known as Icaridin in Canada.

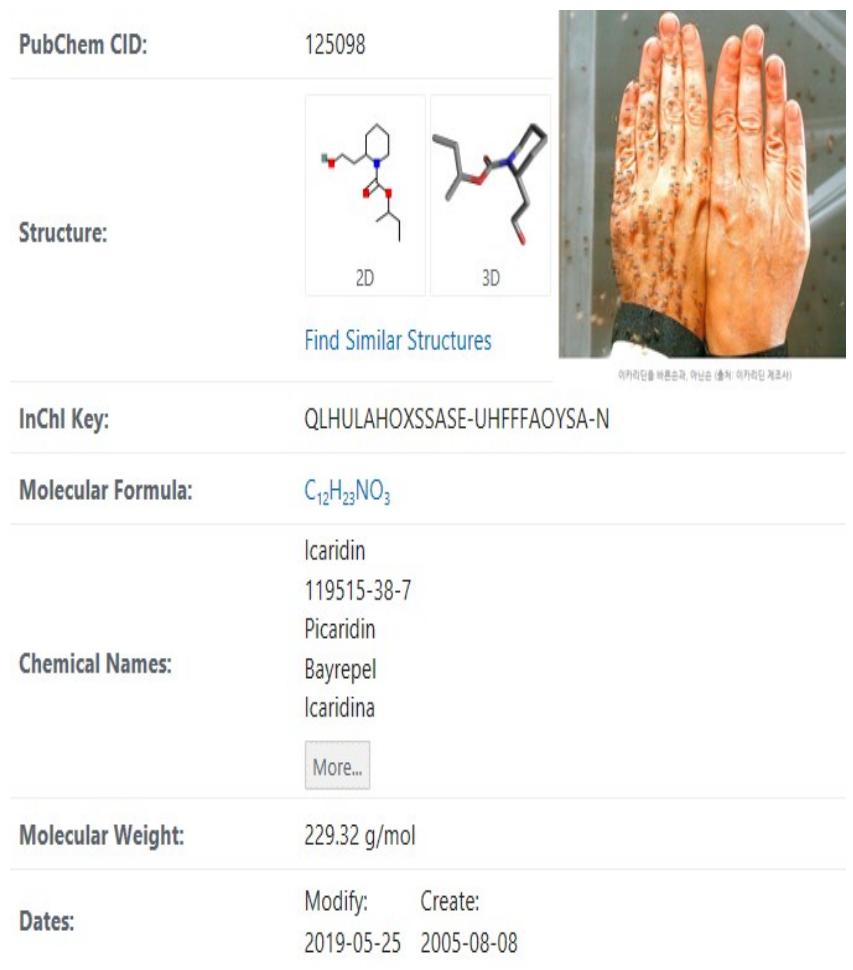

Figure 1: Icaridine Properties

Figure 1 shows icaridin properties in more detail. An active ingredient for personal mosquito protection registered with the U.S. Environmental Protection Agency
(EPA). Colorless and intangible, used from infants to adults, judged highly stable, first used in Europe in 2001, and now available worldwide. The mosquito repellent containing Icaridin is a highly suitable ingredient for recreational equipment and cloth or textile products because it does not dissolve plastics or acrylic.

\subsubsection{IR3535(ethyl butyl acetyl amino propionate)}

Similar to the natural structure of beta-alanine, safety is high, and can be used from infants to adults. Wild mosquito killer used to remove mites, and fur mites.

\subsubsection{Direction of the square}

The bean leaf is called Gwak, and its leaf is similar to the broad bean leaf, so it is called Patchouli. It has a unique smell, tastes spicy and has a slightly warm temper, and reports gastric secretion, sedation, geostationary, dryness, and heat wave. It eliminates heat eating by making you sweat. It strengthens the function of your stomach to help digestion, stops vomiting, is used when you have stomach cramps, heartburns, stomachaches, stomachaches, stomachaches, stomachaches, stomachaches, headaches. It works well for humidification, summer colds, indigestion, indigestion, nausea, vomiting, diarrhea, diarrhea. Opticaloriented oils are known as the best oils in skin care for their regenerative effects, disinfection, moisturizing and cooling of tissues. It is also used in the treatment of such symptoms as ulcers of mucous membranes, cracks, scars, dermatitis, eczema, and fungal and parasitic skin infections, and is highly sterilizable. For this reason, it is used for severe acne and is useful for symptoms such as anxiety, stress, and depression.

\section{Data and research methodology}

\subsection{Approaches and research details}

In order for natural mosquito repellent products containing vegetable oil to enter the market, they must obtain permission and certification for non-drug products from the Ministry of Food and Drug Safety (KFDA). However, mosquito skin products containing only natural substances take a long time to clinical cost of assessment items such as mold material stability and safety, and the cost of obtaining permits as nonmedical products is significantly higher, so in this study, based on natural water-based plant extraction oil that can replace them and the Icaridin material that has been checked for stability, we are trying to maximize the effect of the production by creating optimal mixing ratio standardization. In addition, the company developed a technology to grow, extract and oil the main ingredient of the mine, and developed an 
optimal spray-type desiccant based on a safety test and other evaluation items.

\subsection{Extraction manufacturing process}

With the world's only state-of-the-art herb distillation extractor that can extract herbs, phytoncide, native plant essential oils, hydrosol and super hydrosol at once, the mineral-oriented oil can be extracted by water vapor distillation method and two methods of directly extracting dried leaves. In general, the extraction yield is about $10 \%$, and the extraction time is about 5 hours, and if using the water vapor distillation method, a method of destroying the cell membrane of the photorealistic leaves before water vapor distillation can be used. Experiments have shown that the water vapor distillation method of each dried plant, for example, extracts only low-molecular volatile compounds from flowers, leaves, stems, branches, buds, roots, berries, seeds, etc., and the stem oil has a higher content of parsley alcohol compared to the leaves.

\subsubsection{Main function}

- Herb. Phytoncide. Essential oils of the scent of plants and plant essential oils and herbs such as lavender, rosemary, mint extract hydrozole the extraction functions.

- Phytoncitten oil and hydrozole extraction function of pine, fir, pine, cypress, cedar, etc.

- Essential Oil and Hydrozole Extraction Functions for Domestic Self-Survival Plants such as Worm, Sankook, Hyangyu, and Gujeolcho

- Super hydrozole extraction of herbs (special functions only found in this machine)

- Extractor of new function that collects volatile gases before essential oil is extracted, enabling edible (mineral water, alcohol extraction) as well as extraction for cosmetics (alcohol or glycerine extraction)

- Easily operated by anyone, suitable for educational and farm extraction

- Extractors can be extracted from 150 to $200 \mathrm{~L}$ for testing and farm production.

- Two heaters can be installed ( $2 \mathrm{kw})$ to simultaneously use two heaters. If only one heater is used, it can extract both soft and strong scents at the same time.

- The extractor as shown in figure 2 consists of the main body, the cooling tower and the water separator, and is designed with a convenient workability and workable structure for women. The internal structure of the body consists of three-stage trays, which can reduce workability and extraction time.

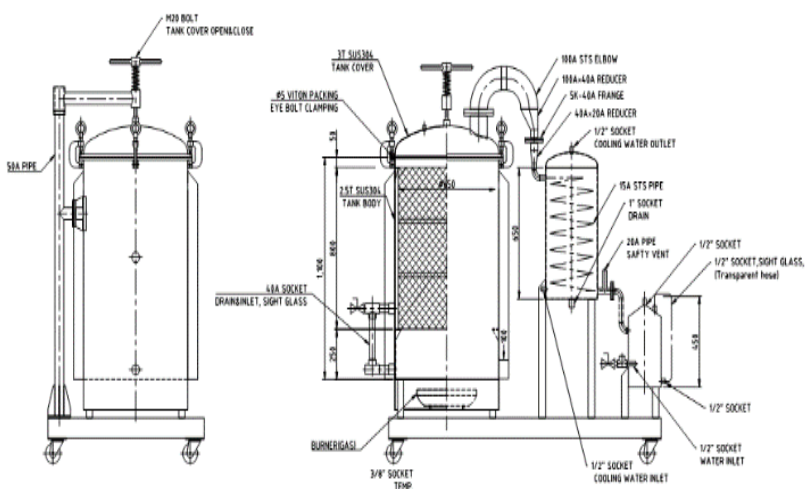

Figure 2: Herb distillation extractor

3.2.2. Specifications for herb amplifier: spec of distillatory

- Capacity (CAPACITY):150 L

- Material (MATERIAL): ST304

- Installation area: $2 \mathrm{X} 1.5 \mathrm{X} 1.5 \mathrm{M}$

- USE

EXTRATION OF HERB ESSENTIAL OIL EXTRATION OF HERB HYDROSOL WATER

EXTRATION OF HERB SUPER HYDROSOL WATER

-Function required by the machine (FUTIONAL OF MACHINE)

Heating: Electrical (ELECTRIC HEATER)

Automatic control system (temperature, time, pressure control) (OTOMATIC CONTROLL SYSTEM)

-High-Efficiency Cooling System(HIGH FUNCTIONAL COLLING SYSTEM)

-Automatic Water Separation System(OTOMATIC W/O SEPERATER)

-Low Temperature Super Hydrozole Extraction Function(SUPER HYDROSOL)

-Multi-Step Design Method of Hub-Injection Container(TRIPLE TRAY)

- Water level measuring instrument for extractor body and oil and water separator(WATER LEVEL CHECK

SYSTEM)

-Temperature and pressure gauge (TEMPERATURE.PRESSER GAGE)

- The body-shattering machine circulation system of cooler water.(COLLING CIRCULATION SYSTEM)

-Upper discharge method of oil and water separator(SEPERATION OF ON SIDE)

\subsection{Calculation of mosquito repellent composition and optimal extraction ratio}

Table 4 indicates composition proportion of mosquito repellent ingredient per $100 \mathrm{ml}$. The Korea Food and Drug Administration (KFDA) recognizes that it has a mosquito repellent effect of at least 7 percent - less than 24 percent. 
This is strongly recommended as a substitute for existing DEETs in the World Health Organization (WHO), the American Centers for Disease Control (CDC), and the European Centers for Disease Control (EUC) as the material that Icaridin has long been used to avoid mosquitoes and has proven to be avoided and safe with materials developed by the world-famous German company Bayer. It is already becoming common in developed countries, and its effectiveness and stability have been proven. In this study, the main ingredient was set to Icaridin (7\% minimum content), and the 'kwanggokhyang (patchouli) extract, which proved effective in oriental medicine, was used as raw material to conduct a more mosquito skin persistence test to calculate the optimal mixing ratio.

Table 4: Composition proportion of mosquito repellent ingredient

\begin{tabular}{|c|c|c|c|}
\hline No. & Ingredient & Proportion(\%) & Part \\
\hline 1 & Purified water & 32.1 & Dispersant, base \\
\hline 2 & Ethanol(85\%) & 37.5 & Solvent \\
\hline 3 & Lavender water & 10.0 & Flavor \\
\hline 4 & PEG-8 & 10.0 & Emulsifying aids \\
\hline 5 & $\begin{array}{c}\text { Polyoxyethylene } \\
\text { hydrogenated caster oil }\end{array}$ & 1.0 & Emulsifier \\
\hline 6 & Citric acid & 1.0 & pH control agents \\
\hline 7 & Icaridin & 7.0 & $\begin{array}{c}\text { Mosquito } \\
\text { repellents }\end{array}$ \\
\hline 8 & Patchouli oil & 0.6 & $\begin{array}{c}\text { Mosquito } \\
\text { repellents }\end{array}$ \\
\hline 9 & Cinnamon Bark oil & 0.1 & $\begin{array}{c}\text { Mosquito } \\
\text { repellents }\end{array}$ \\
\hline 10 & Rose Geranium oil & 0.2 & Flavor \\
\hline 11 & Ylang Ylang Oil & 0.2 & Flavor \\
\hline 12 & $\begin{array}{c}\text { Baby Powder Fragrance } \\
\text { oil }\end{array}$ & 0.3 & Flavor \\
\hline & Total & 100 & \\
\hline
\end{tabular}

\section{Results}

\section{1. pH measurement}

The $\mathrm{pH}$ measurement was measured by placing the mosquito repellent in a container (Test method No. 2019-45 of the Environmental Ministry Notice No. 2019-45), and using a $\mathrm{pH}$ meter from Metrohm AG. In order to secure reliability of measurement, it was requested to analyze it through KCL (Korea Institute of Environmental Testing) of the international public organization, and the results of the measurement of mosquito repellent $\mathrm{pH}$ showed a stable $\mathrm{pH}$ value in the range of 4-7. The mosquito repellent $\mathrm{pH}$ should remain neutral.
Acid and alkali may cause corneal damage or harmful effects on the human body.

Table 5: Evasion Rate According to Concentration of Repellent Solution

\begin{tabular}{|c|c|c|c|c|c|}
\hline Count & $\begin{array}{c}\text { Density } \\
(\mu \mathrm{l} / 1 \mathrm{ml})\end{array}$ & Control & Evasion & $\begin{array}{c}\text { Not } \\
\text { Evasion }\end{array}$ & $\begin{array}{c}\text { Evasion } \\
\text { Rate } \\
(\%)\end{array}$ \\
\hline 1 & 1 & 11 & 5 & 6 & 0.45 \\
\hline 1 & 2 & 11 & 6 & 5 & 0.55 \\
\hline 1 & 3 & 11 & 7 & 4 & 0.64 \\
\hline 2 & 0.2 & 10 & 3 & 7 & 0.30 \\
\hline 2 & 0.4 & 10 & 8 & 2 & 0.80 \\
\hline 2 & 0.6 & 10 & 8 & 2 & 0.80 \\
\hline 2 & 1 & 10 & 8 & 2 & 0.80 \\
\hline 3 & 0.2 & 13 & 4 & 9 & 0.31 \\
\hline 3 & 0.4 & 13 & 3 & 10 & 0.23 \\
\hline 3 & 0.6 & 13 & 4 & 9 & 0.31 \\
\hline 3 & 1 & 13 & 6 & 7 & 0.46 \\
\hline 3 & 2 & 13 & 6 & 7 & 0.46 \\
\hline 3 & 3 & 13 & 8 & 5 & 0.62 \\
\hline 3 & 5 & 13 & 9 & 4 & 0.69 \\
\hline 3 & 10 & 13 & 10 & 3 & 0.77 \\
\hline 3 & 20 & 13 & 12 & 1 & 0.92 \\
\hline 4 & 0.2 & 11 & 3 & 8 & 0.27 \\
\hline 4 & 0.6 & 11 & 6 & 5 & 0.55 \\
\hline 4 & 1.6 & 11 & 4 & 7 & 0.36 \\
\hline 4 & 2.6 & 11 & 7 & 4 & 0.64 \\
\hline 4 & 4.6 & 11 & 6 & 5 & 0.55 \\
\hline 4 & 9.6 & 11 & 9 & 2 & 0.82 \\
\hline 4 & 19.6 & 11 & 10 & 1 & 0.91 \\
\hline 5 & 0.2 & 15.5 & 3.5 & 12 & 0.23 \\
\hline 5 & 1.2 & 15.5 & 7.5 & 8 & 0.48 \\
\hline 5 & 2.2 & 15.5 & 9.5 & 6 & 0.61 \\
\hline 5 & 7.2 & 15.5 & 12.5 & 3 & 0.81 \\
\hline 5 & 12.2 & 15.5 & 13.5 & 2 & 0.87 \\
\hline 5 & 22.2 & 15.5 & 14.5 & 1 & 0.94 \\
\hline 6 & 0.2 & 11 & 4 & 7 & 0.36 \\
\hline 6 & 0.6 & 11 & 5 & 6 & 0.45 \\
\hline 6 & 1.6 & 11 & 7 & 4 & 0.64 \\
\hline 6 & 2.6 & 11 & 9 & 2 & 0.82 \\
\hline 6 & 3.6 & 11 & 10 & 1 & 0.91 \\
\hline 7 & 0.2 & 11 & 4 & 7 & 0.36 \\
\hline 7 & 0.7 & 11 & 6 & 5 & 0.55 \\
\hline 8 & 0.2 & 11 & 3 & 8 & 0.27 \\
\hline 8 & 0.4 & 11 & 4 & 7 & 0.36 \\
\hline 8 & 0.9 & 11 & 5 & 6 & 0.45 \\
\hline 8 & 1.9 & 11 & 8 & 3 & 0.73 \\
\hline 8 & 2.9 & 11 & 9 & 2 & 0.82 \\
\hline 8 & 7.9 & 11 & 10 & 1 & 0.91 \\
\hline 8 & 12.9 & 11 & 9 & 2 & 0.82 \\
\hline 8 & 22.9 & 11 & 10 & 1 & 0.91 \\
\hline
\end{tabular}




\subsection{Viscosity measurement}

The viscosity measurement is measured for 1 minute at $60 \mathrm{rpm}$ using a spindle at $25^{\circ} \mathrm{C}$. The instrument was measured using a Brookfield viscometer. In order to secure reliability of measurement, the average point of mosquito repellent kept at room temperature $\left(25^{\circ} \mathrm{C}\right)$ was also measured below 5ps. The viscosity of the repellent must be maintained at an appropriate level, affects mixing and duration of ingredients.

Table 6: Evasion Rate-Repellent

\begin{tabular}{|c|c|c|c|}
\hline \multirow{2}{*}{ Probability } & \multicolumn{3}{|c|}{ 95\% Confidence Limits for Density } \\
\hline & Estimate. & Lower Bound & Upper Bound \\
\hline PROBIT 010 & -25.451 & -36.545 & -19.128 \\
\hline .020 & -22.362 & -32.284 & -16.679 \\
\hline .030 & -20.402 & -29.582 & -15.153 \\
\hline .040 & -18.928 & -27.550 & -13.991 \\
\hline .050 & -17.728 & -25.898 & -13.045 \\
\hline .060 & -16.708 & -24.493 & -12.238 \\
\hline .070 & -15.813 & -23.261 & -11.531 \\
\hline .080 & -15.011 & -22.159 & -10.897 \\
\hline .090 & -14.283 & -21.157 & -10.320 \\
\hline .100 & -13.612 & -20.236 & -9.788 \\
\hline .150 & -10.834 & -16.425 & -7.580 \\
\hline .200 & -8.627 & -13.408 & -5.816 \\
\hline .250 & -6.733 & -10.830 & -4.290 \\
\hline .300 & -5.032 & -8.529 & -2.906 \\
\hline .350 & -3.456 & -6.416 & -1.605 \\
\hline .400 & -1.961 & -4.438 & -.343 \\
\hline .450 & -.514 & -2.565 & .919 \\
\hline .500 & .910 & -.785 & 2.224 \\
\hline .550 & 2.334 & .899 & 3.625 \\
\hline .600 & 3.781 & 2.480 & 5.178 \\
\hline .650 & 5.276 & 3.973 & 6.925 \\
\hline .700 & 6.852 & 5.426 & 8.886 \\
\hline .750 & 8.553 & 6.907 & 11.090 \\
\hline .800 & 10.447 & 8.496 & 13.605 \\
\hline .850 & 12.654 & 10.303 & 16.580 \\
\hline .900 & 15.432 & 12.541 & 20.360 \\
\hline .910 & 16.103 & 13.078 & 21.277 \\
\hline .920 & 16.831 & 13.660 & 22.274 \\
\hline .930 & 17.633 & 14.298 & 23.371 \\
\hline .940 & 18.528 & 15.010 & 24.598 \\
\hline .950 & 19.549 & 15.821 & 25.999 \\
\hline .960 & 20.748 & 16.772 & 27.646 \\
\hline .970 & 22.222 & 17.939 & 29.674 \\
\hline .980 & 24.182 & 19.487 & 32.371 \\
\hline .990 & 27.271 & 21.923 & 36.627 \\
\hline
\end{tabular}

\subsection{Effective capacity test results}

The results of eight iterations of the undiluted solution different concentrations were shown in Table 5. And the data were analyzed through a regression analysis, as shown in table 6, using the statistical program SPSS to obtain a capacity of $50 \%$ and $99 \%$.

\subsection{Results of mosquito repellent test}

\section{- Results of avoidance rate due to avoidance effect}

The skin surface area of the arm for the avoidance force test can be measured as an approximation based on the cylindrical surface area. For the surface area calculation, the length of the treatment area, the distal and proximal boundary lengths of the treatment area are required. Table 7 shows the test results calculated on the skin surface area.

Table 7: Skin surface area calculation test result

\begin{tabular}{|c|c|c|c|c|c|}
\hline No. & Test subject & Skin surface $\left(\mathbf{c m}^{\mathbf{2}}\right)$ & $\mathbf{B}(\mathbf{c m})$ & $\mathbf{C}(\mathbf{c m})$ & $\mathbf{D}(\mathbf{c m})$ \\
\hline 1 & Female1 & 591.25 & 18 & 29.3 & 25 \\
\hline 2 & Female2 & 550 & 18 & 26 & 25 \\
\hline 3 & Male1 & 621 & 18 & 28 & 27 \\
\hline 4 & Male2 & 602 & 16 & 27 & 28 \\
\hline 5 & Female3 & 585 & 18 & 27 & 26 \\
\hline 6 & Male3 & 660 & 17 & 27 & 30 \\
\hline 7 & Male4 & 587.25 & 17 & 26.5 & 27 \\
\hline 8 & Male5 & 705 & 18 & 29 & 30 \\
\hline 9 & Female4 & 580.5 & 17 & 26 & 27 \\
\hline 10 & Male6 & 624 & 16 & 23 & 32 \\
\hline
\end{tabular}

- Test results of duration avoidance rate according to the avoidance effect

Based on the results obtained from the effective dose test results, a type of repeater was developed and a test specimen was manufactured to conduct a avoidance rate test and a duration test. Voice control is a skin that does not apply a repeater, positive control is a repeater containing $7 \%$ Icaridin, and test (product) mosquito repellent is a final product developed based on effective capacity. Table 8 shows the results of repeated comparative tests with control groups ( $7 \%$ Icaridin) for the avoidance rate according to the duration of the test. As a result of the average avoidance rate over time, the control group showed a minimum of $77 \%$ to a maximum $100 \%$ after five hours, and a minimum of $90 \%$ to a maximum of $100 \%$ for test product avoidance. 
Table 8: Evasion Effect by Duration

\begin{tabular}{|c|c|c|c|c|c|c|c|c|}
\hline $\begin{array}{c}\text { Test } \\
\text { subject }\end{array}$ & $\begin{array}{c}\text { Negative } \\
\text { Control }\end{array}$ & \multicolumn{6}{|c|}{ Positive control group(7\% Icaridin + Patchouli oil) } \\
\hline & & $\begin{array}{c}0 \mathrm{~min}- \\
30 \mathrm{~min}\end{array}$ & $\begin{array}{c}30 \mathrm{~min}- \\
1 \mathrm{~h}\end{array}$ & $\begin{array}{c}1 \mathrm{~h}- \\
1 \mathrm{~h} 30 \mathrm{~m}\end{array}$ & $2 \mathrm{~h}$ & $3 \mathrm{~h}$ & $4 \mathrm{~h}$ & $5 \mathrm{~h}$ \\
\hline $\begin{array}{c}\text { Female } \\
1\end{array}$ & 32 & 0 & 0 & 0 & 1 & 2 & 1 & 2 \\
\hline $\mathrm{R}(\%)$ & & 100.0 & 100.0 & 100.0 & 96.9 & 93.8 & 96.9 & 93.8 \\
\hline $\begin{array}{c}\text { Female } \\
2\end{array}$ & 25 & 0 & 0 & 0 & 0 & 0 & 2 & 3 \\
\hline $\mathrm{R}(\%)$ & & 100.0 & 100.0 & 100.0 & 100.0 & 100.0 & 92.0 & 88.0 \\
\hline Male 1 & 22 & 0 & 0 & 0 & 0 & 2 & 2 & 4 \\
\hline $\mathrm{R}(\%)$ & & 100.0 & 100.0 & 100.0 & 100.0 & 90.9 & 90.9 & 81.8 \\
\hline Male 2 & 32 & 0 & 0 & 0 & 0 & 0 & 0 & 1 \\
\hline $\mathrm{R}(\%)$ & & 100.0 & 100.0 & 100.0 & 100.0 & 100.0 & 100.0 & 96.9 \\
\hline $\begin{array}{c}\text { Female } \\
3\end{array}$ & 29 & 0 & 0 & 0 & 0 & 0 & 0 & 1 \\
\hline $\mathrm{R}(\%)$ & & 100.0 & 100.0 & 100.0 & 100.0 & 100.0 & 100.0 & 96.6 \\
\hline Male 3 & 40 & 0 & 0 & 0 & 0 & 0 & 1 & 0 \\
\hline $\mathrm{R}(\%)$ & & 100.0 & 100.0 & 100.0 & 100.0 & 100.0 & 97.5 & 100.0 \\
\hline Male 4 & 31 & 0 & 0 & 0 & 0 & 2 & 4 & 5 \\
\hline $\mathrm{R}(\%)$ & & 100.0 & 100.0 & 100.0 & 100.0 & 93.5 & 87.1 & 83.9 \\
\hline Male 5 & 21 & 0 & 0 & 0 & 0 & 0 & 2 & 4 \\
\hline R(\%) & & 100.0 & 100.0 & 100.0 & 100.0 & 100.0 & 90.5 & 81.0 \\
\hline $\begin{array}{c}\text { Female } \\
4\end{array}$ & 42 & 0 & 0 & 0 & 0 & 1 & 1 & 2 \\
\hline R(\%) & & 100.0 & 100.0 & 100.0 & 100.0 & 97.6 & 97.6 & 95.2 \\
\hline Male 6 & 16 & 0 & 0 & 0 & 2 & 2 & 3 & 3 \\
\hline R(\%) & & 100.0 & 100.0 & 100.0 & 87.5 & 87.5 & 81.3 & 81.3 \\
\hline
\end{tabular}

\section{Conclusions}

The mosquito repellent is a non-medical product that requires permission from the Korea Food and Drug Administration (KFDA) to prevent mosquito-borne diseases (such as dengue fever and malaria) in advance. The main objective of this study is to grow and develop the costefficient ingredients of the oreum hyang (patchouli) plant and extract oil using herbal distillation extractors to examine the efficacy of mosquito repellents containing natural ingredients and compounds (icaridin) and calculate the optimal mixing ratio. We reviewed existing natural and Icaridin synthetic materials to complete the development of mosquito repellent products with good stability and carried out clinical tests through the Korea Food and Drug Administration Notice_ B1-2015-3-006 Guidelines. The analysis of the physical and chemical components was commissioned by the state agency to ensure reliability. The results of the area and avoidance tests of mosquito repellent developed in this study are as follows.

1. Experiments in the skin surface area and voice control of the participants showed that men had $8.9 \%$ wider skin surface area than women, while tests in voice control showed that women were bitten five times more than men. The t-test results, on the other hand, showed no significant difference with $\mathrm{p}$-value of 0.755 .

2. Both the positive and the experimental control groups had a valid duration of up to three hours, but from the time of five hours, the positive control group had $77 \%$ and the experimental control had $90 \%$, indicating a difference of $14.4 \%$ over the positive control group.

3. Resistant persistence differed by gender. In the case of the positive control group, the difference in persistence between men and women was 5.16, and the maximum difference in the experimental control group was 4.28.

In this experiment, it is believed that the survey of individual characteristics may be used as a basic data reflecting and supplementing the experimental plan considering the individual characteristics in future studies as there are limitations to the characteristics between the variables of voice and positive control groups and experimental control groups. Therefore, the mosquito repellents developed in this study on the basis of safety and continuity are very cost-effective in terms of mosquito repellent effect, fragrance, odor removal, perfume, ink, skin care and massage. This cost-effective technology and mosquito repellent are thought to contribute to new distribution processes and industries in this field.

\section{References}

Yuliani, A., \& Sri, H. A. (2012). Evaluation of PhysicoChemical Properties of Patchouli Oils (Pogostemon cablin) Separated by Fractional Distillation Method. Paper presented at the 8th IMT-GT Uninet Biosciences Conferences, Banda Aceh, Indonesia (pp. 22-24).

Lawal, H. O., Adewuyi, G. O., Fawehinmi, A. B., \& Etatuvie, S. O. (2013). Chemical evaluation of mosquito repellent formulation prepared from the essential oil of plants. Journal of Natural Products, 6(2013), 33-37.

Hu, L. F., Li, S. P., Cao, H., Liu, J. J.,Gao, J. L., Yang, F. Q., \& Wang, Y. T. (2006). GC-MS fingerprint of Pogostemon cablin in China. Journal of Pharmaceutical and Biomedical Analysis, 42(2006), 2224.

Kusuma, H. S., \& Mahfud, M. (2017). GC-MS analysis of essential oil of Pogostemon cablin growing in Indonesia extracted by microwave-assisted hydrodistillation. International Food Research Journal, 24(4), 1525-1528

Teris, A. B., \& Daniel, J. (2017). The essential oil of patchouli, Pogostemon cablin : A review. Flavour and Fragrance Journal, 33(1), DOI: 10.1002/ffj.3418.

Park, S. H., Oh, H. W., Kwon, H. R., Seo, M. J., Yu, Y. M., \& Youn, Y. N. (2014). Insecticidal Activities of 
Tussilago farfara Extracts against Culex pipiens pallens and Tetranychus urticae. CNU Journal of Agricultural Science, 41(2), 177-185.

Park, J. H., Ryu, K. Y., Jee, H. J., Lee, B. M., \& Gho, H. G. (2008). Evaluation of Insecticidal Activity of Plant Extracts against Three Insect Pests. Korean Society of Applied Entomology, 47(1), 59-64

Kyung, S. H., \& Yoon, Y. H. (1999). Evaluation of Insecticidal Activity of Plant Extracts against Three Insect Pests. The Korean Society of Pesticide Science, 3(1), 46-50.

Choi, I. J., Kwon, H. H., Lee, H. H., Son, H. G., Hong, S. G., Kang, J. W., \& Park, Y. S. (2013). Evaluation of Insecticidal Activity of Plant Extracts against the Diamondback Moth, Plutella xylostella (Lepidoptera: Plutellidae) on Vegetable Plant. Korean J Plant Res, 26(1), 19-25.

Kim, S. G., Jin, J. H., Lim, C. K., Jang, H. H., \& Cho, S. Y. (2009). Evaluation of Insecticidal Efficacy of Plant Extracts Against Major Insect Pests. The Korean Journal of Pesticide Science, 13(3), 165-170.

Kim, K. W., \& Kim, S. Y. (2005). Herbicidal and Fungicidal Activities of Methanol Extracts from Native Plants in Korea. The Korean Journal of Weed Science, 25(3), 221-232.

Baik, J. A., Song, M., \& Jang, M. H. (2010). Insecticidal Effect of Some Local Native Fragrant Plantson Larvae of the Mosquito. Korean Society for Horticultural Science, 28(S1), 170-171

Chang, I. C., \& Hwang, H. G. (2007). Physicians' acceptance of pharmacokinetics based clinical decision support systems. Expert Systems with Applications, 33(2), 296-303.

Kijsanayotin, B., Pannarunothai, S., \& Speedie, S. M. (2009). Factors influencing health information technology adoption in Thailand's community health centers: Applying the UTAUT model. International
Journal of Medical Informatics, 78(6), 404-416.

Kim, H. K., \& Kim, W. K. (2017). An Exploratory Study for Artificial Intelligence Shopping Information Service. Journal of Distribution Science, 15(4), 69-78.

Miltaen, C. L., Popovic, A., \& Oliveria, T. (2013). Determinants of end-user acceptance of biometrics: Integrating the "Big 3" of technology acceptance with privacy context. Decision Support Systems, 56, 103-114.

Parasuraman, A., Zeithaml, V. A., \& Malhotra, A. (2005). ES-QUAL a Multiple-item Scale for Assessing Electronic Service Quality. Journal of Service Research, 7(3), 213-233.

Sadhya, D., \& Singh, S. K. (2016). Privacy preservation for soft biometrics based multimodal recognition system. Computers \& Security, 58, 160-179.

Salisbury, R. P., Pearson, A., \& Miller, D. W. (2001). Identifying barriers that keep shoppers off the World Wide Web: developing a scale of perceived web security. Industrial Management \& Data Systems, 101(4), 165176.

Touray, A., Salminen, A., \& Murse, A. (2014). Internet adoption at the User Level: Empirical Evidence from The Gambia. Information Technology for Development, 21(2), 281-296.

Venkatesh, V., \& Bala, H. (2008). Technology acceptance model 3 and a research agenda on interventions. Decision Sciences, 39(2), 273-315.

Wei, J., Lowry, P. B., \& Seedorf, S. (2016). The assimilation of RFID technology by Chinese companies: A technology diffusion perspective. Information \& Management, 52(6), 625-642.

Wua, J. H., \& Wang, S. H. (2005). What drives mobile commerce? An empirical evaluation of the revised technology acceptance model. Information \& Management, 42(5), 719-7. 